\title{
Measuring Quality of Life in Adult Patients with Chronic Tonsillitis
}

\author{
Theodoros Skevas*, Christoph Klingmann, Serkan Sertel, Peter K. Plinkert and Ingo Baumann
}

Department of Otorhinolaryngology, Head and Neck Surgery, University of Heidelberg, Germany

\begin{abstract}
The effects on quality of life (QoL) in adult patients with chronic tonsillitis are multidimensional. Tonsillectomy has been and is still the standard for treating these patients, who fulfil certain clinical criteria, and is thus the main determinant in the change of QoL. The reduction in severity and frequency of symptoms, health care utilization, physician visits and days off work are major factors in the improvement of QoL. Other important aspects are the management of the postoperative pain and the avoidance of post tonsillectomy hemorrhage. Economic benefits of tonsillectomy receive increasing attention as there can be direct associations with the patients' QoL. Studies concerning the clinical efficacy of tonsillectomy, various techniques in order to achieve the best outcome, postoperative pain relieving measures, methods to minimize postoperative hemorrhage rates, and studies of cost-effectiveness of this intervention will be reviewed and discussed.
\end{abstract}

Keywords: Tonsillectomy, post-tonsillectomy bleeding, efficacy, post-operative pain.

\section{BACKGROUND}

Chronic tonsillitis is one of the most common otorhinolaryngological diseases and tonsillectomy continues to be one of the most common surgical procedures as well as the standard for treating adults with this clinical entity [1]. The determinants of the quality of life (QoL) of patients with chronic tonsillitis are multidimensional and especially after surgical therapy the outcome of the therapeutic intervention is the main factor associated with the change of QoL in these patients. The outcome is a construct of many different endpoints, whereby physicians and patients give their own assessments [2]. There is no standard definition of QoL, but health services researchers agree that QoL must be measured from the patient's perspective $[3,4]$. A positive outcome as to the improvement in QoL of the patient is dependent primarily on a reduction in number and frequency of symptoms, days of work missed, doctor visits, antibiotic usage and also, indirectly, on long-term financial savings through avoidance of the aforementioned circumstances. Secondary factors associated primarily, but not only, to a short term influence on QoL include the regulation of postoperative pain and the incidence of post-tonsillectomy hemorrhage. These factors could be complemented with observations about the delay in scheduling the operation, the duration of the operation, the intraoperative blood-loss, the doctor-patient rapport and the duration of the hospital stays or the frequency of necessary readmissions. Until now most of the studies concerning QoL in patients with chronic tonsillitis have been done on children and only a few studies exist on adults. The goal of the present review is to display the latest data of studies concerning the QoL of adults with chronic tonsillitis and to present the main aspects that influence QoL in adults with chronic tonsillitis, focusing especially in the change in QoL after tonsillectomy.

*Address correspondence to this author at the Department of Otorhinolaryngology, Head and Neck Surgery, University of Heidelberg, Im Neuenheimer Feld 400, D-69120, Heidelberg, Germany; Tel: +49-62215636757; Fax: +49-6221-567478;
E-mail: theodoros.skevas@med.uni-heidelberg.de

1. Is Tonsillectomy an Effective Procedure in Adult Patients with Chronic Tonsillitis?

There is still controversy about the effectiveness of tonsillectomy in adults as there is a lack of high-level evidence. The highest-level evidence for the efficacy of this surgical procedure is in pediatric patients with recurrent tonsillitis [5]. In case of tonsillectomy, high level evidence is difficult to obtain, given the ethical objections that would arise when including a suitable surgical control group in a randomised, controlled trial. Hitherto mostly retrospective studies and only few prospective clinical trials on the efficacy of tonsillectomy have been performed including adults (Table 1).

In a multicenter, prospective observational outcomes study by Witsell et al. tonsillectomy led to a statistically significant reduction in the number of sore throats, days of work missed, doctor visits for sore throats, antibiotic usage, and halitosis for both the 6-month and 1-year follow-up periods $(p<0.0001)$. Statistically significant changes in both disease-specific and global QoL after tonsillectomy were observed. Concretely, significant improvements $(p<0.0001)$ were seen in all 6 subscales of the disease specific QoLmeasuring instrument, the Tonsil and Adenoid Health Survey Instrument (TAHSI), that included infection, health care utilization, eating and swallowing, cost of care, behaviour, and airway and breathing. TAHSI is a diseasespecific QoL questionnaire for tonsil and adenoid disease, which was validated for children, aged 2-16. Because of the lack of validated disease specific QoL instruments for adults, and due to its face validity, as most of the content was appropriate for adults, with some appropriate additional question modifications, it was used in adults. Changes in global QoL were measured with the SF-12, a validated global QOL instrument for adults, which is scored into 2 subscales: physical functioning and emotional functioning. The mental components subscale (MCS) and the physical components subscale (PCS) both showed significant 
improvements at 6 months, but at 1 year only the PCS showed a statistical significant improvement. Limitations of this study such as the lack of a control group, selection bias, placebo effect and reporting bias should be considered when interpreting the study findings. However the authors argue that the magnitude and duration of improvement seem, despite the former considerations, to indicate a significant improvement in QoL after tonsillectomy [6]. Koskenkorva et al. conducted a prospective cohort study of adult patients with recurrent tonsillitis undergoing tonsillectomy. They found a significant improvement in QoL according to all the Glasgow Benefit Inventory (GBI) Questionnaire subscales, which is a validated instrument for retrospective evaluation after otorhinolaryngological procedures [7], indicating that patients gained benefits not only in terms of general health but also in social and physical ones. The highlight of their study was that the most significant factor predicting patient satisfaction, as well as improvement in QoL, was morbidity before tonsillectomy. Patients, who suffered only spasmodic tonsillitis episodes and infrequent throat pain and fever during the 3-6 months before tonsillectomy, were less satisfied 6 months after the operation, compared with patients who had suffered more frequent attacks. This fact emphasises the importance of obtaining as accurate information as possible about the patient's past throat infections and symptoms. Post-tonsillectomy improvement in QoL was not influenced by patient demographics or the size or quality of the tonsils assessed pre- or peri-operatively. With a response rate of $89 \%$ a noteworthy bias is not probable. Recall bias could be a limitation of this study, but the authors point out that retrospective assessment of the QoL after an intervention appears to provide information that is more sensitive to change and more highly correlated with patient satisfaction, compared with serial change data $[8,9]$.

A retrospective survey by Akgun et al. of adults and children, who had undergone tonsillectomy for recurrent acute and chronic tonsillitis, showed that tonsillectomy significantly reduced general practitioner attendances and days off work/school due to sore throat and resulted in an improved feeling of health and well-being, thus concluding that tonsillectomy is of benefit for such patients. The lack of an effective control group, the anecdotal way of obtaining the data, the limited amount of patients $(n=100)$, and the possibility of questioning bias should be considered as weaknesses when interpreting the results of this study [10]. Another retrospective study by Hsu et al. examined the mean frequency of tonsillitis per year, the mean duration in days of each episode of tonsillitis, the mean work days missed, and the mean duration in days of poor food intake, in 105 adults with recurrent tonsillitis before and after tonsillectomy. Decreases in all measurements after tonsillectomy were shown to be statistically significant $(p<0.005) .92 .4 \%$ of the patients would still choose tonsillectomy again for the same condition and $98.1 \%$ would recommend tonsillectomy to family or friends if they had recurrent tonsillitis, thus emphasizing the benefit and satisfaction after surgery [11]. Fujihara et al. conducted a retrospective study in Japan, including children and adults (total $n=41$ ), who underwent tonsillectomy, also showing a clinical effectiveness of the procedure as the number of sore throat episodes with fever, the number of physician visits, missed work days/absent school days were significantly lower than before tonsillectomy (in adults $\mathrm{p}<0.0001$ and in children $\mathrm{p}<0.005$ respectively) [12]. In the two former studies similar limitations could be noticed, as in the study by Akgun et al. A further retrospective analysis in adults by Mui et al. demonstrates the efficacy of tonsillectomy by showing a statistically significant reduction in the mean number of clinic visits for throat infection $(p<0.001)$ and the number of prescriptions for oral antibiotics after tonsillectomy $(p<0.001) .88 \%$ reported having fewer sore throats, $87 \%$ having less severe sore throats and $90 \%$ requiring fewer sick days off work or school after tonsillectomy. The authors point out that because the terms pharyngitis, upper respiratory infections and tonsillitis are interchangeably used by physicians, there is lacking consensus for differentiating between pharyngitis and tonsillitis, so the most appropriate clinical indicator for tonsillectomy may be the number of documented throat infections, instead of number of visits that yielded a diagnosis of tonsillitis [13]. The lacks of controls, as well as recall and response bias are also aspects to consider in this retrospective study. In the Scottish tonsillectomy audit a total of 9773 patients (adults and children) were asked retrospectively by means of a questionnaire to evaluate their satisfaction after tonsillectomy. More than $97 \%$ of patients were glad the operation had been performed, while $2 \%$ felt the operation had not helped at all [14]. This study did not, however, use any validated QoL instruments and the indications for tonsillectomy were wider than recurrent tonsillitis including also obstructive symptoms. In another retrospective clinical survey by Kim et al., of 217 patients, including children and adults, undergoing tonsilloadenoidectomy, upper respiratory tract infections, recurrent tonsillopharyngitis, snoring, loss of appetite, easy fatigability, cervical lymphadenitis, mouth breathing, foreign body sensation in the throat and arthralgia, showed improvement after tonsilloadenoidectomy [15]. Also in this study, no validated QoL instruments were used, the operation also included the removal of the adenoids, and the reason for surgery also included other findings, such as otitis media with effusion and obstructive symptoms.

Schwentner et al., in a retrospective manner, also found a significant and long lasting improvement in the health related QoL by means of significant improvement in all GBI scores after tonsillectomy performed either as electro- or cold dissection. The benefit was more pronounced in the general subscale and the physical health subscale than in the social support subscale, thus giving emphasis to the fact that tonsillectomy has an impact not only on the physical but also on the mental health of patients suffering from chronic tonsillitis. They also found no difference in GBI scores in relation to the follow-up time, indicating that the effects of tonsillectomy are stable over time and independent of the technique, either "hot" or "cold", used for patients with chronic tonsillitis. As there was no significant difference in GBI total score and GBI subscores between men and women, authors conclude that gender does not influence QoL after tonsillectomy. The authors could further report a significant difference in GBI subscores in patients with coexistent chronic disease and/or other incriminatory events, hence showing that exact evaluation of the individual medical and social history of each patient might help to achieve better postoperative results in the evaluation of QoL, leading to a higher grade of satisfaction after tonsillectomy. 
Limitations of this study are a potential recall bias and the low response rate of $38 \%$. As to the former, it is commented that despite the controversies in how to best assess change in QoL, especially regarding "response shift" phenomena, retrospective measures of changes in health related $\mathrm{QoL}$ have been found to be sensitive to change and may correlate more strongly with patients' overall satisfaction with the surgical intervention $[1,16,17]$. Statistically significant data suggesting the QoL benefits of tonsillectomy are also illustrated in a retrospective survey of patients aged 15-25 years, who underwent tonsillectomy for chronic or recurrent tonsillitis, by Richards et al. The measuring instrument used was the GBI. The amelioration of the mean total score $(p<0.001)$ shows that tonsillectomy provides an overall $\mathrm{QoL}$ benefit. Significant improvements were also noted in the general well-being $(p<0.001)$ and physical health subscales $(p<0.001)$. A benefit in social function, though, was not depicted $(p>0.05)$. Concerning two possible weaknesses of this study i.e. responder and selection bias, the authors argument that according to Robinson et al. [7] independent analysis of the GBI has shown that the number of years since surgery does not affect the overall score. Further GBI is not disproportionately affected by positive response bias, which characterizes measures of patient satisfaction, and it is sensitive to changes in health status even when the outcome is successful [18].

Bhattacharyya et al. conducted a cross-sectional retrospective survey analysis of patients, aged 16 years or over, at least 1 year after undergoing tonsillectomy performed for chronic infectious tonsillitis. In the QoL measurements with the GBI he found statistically significant benefits on the total score $(p<0.001)$ as well as on all the individual subscores after tonsillectomy $(\mathrm{p}<0.001)$, while in the former study of Richards et al. no benefit was observed in the social functioning subscale. The benefit was significantly more pronounced in the total score and general health subscores than in the social and physical functioning scores, something that suggests that tonsillectomy has wider impacts in the patient's life, which are not restrained only to the amelioration of their physical health. There was also, as in the study of Schwentner et al., no correlation between GBI scores and length of follow-up, suggesting that the benefit of tonsillectomy is long-term. The overall health benefit of tonsillectomy was also emphasized through the statistical significant reduction $(p<0.001)$ in the number of weeks receiving antibiotics for sore throats, the number of workdays missed and the number of physician visits after tonsillectomy. These results demonstrate a substantial decrease in utilization of health care resources and a significant impact on the patient's productivity. Through demographic comparisons between responders and nonresponders and through the division of the cohort into equal populations above and below the median follow-up, which showed no statistically significant difference between groups, the response and recall bias were considered to be minimal. The poor response rate of $26.3 \%$ was acknowledged as another potential limitation of the study. The authors also mark that while patients were asked to assess the impact of chronic tonsillitis in the 2 years surrounding the tonsillectomy, this potentially ignores the variation in disease severity that may occur over time, thus creating the possibility that some percentage of the improvement in QoL may in fact be due to the natural history of the disease. But since there was no positive correlation between QoL improvement and duration of follow-up, the potential impact of this argument is reported to be less likely. Furthermore, to the aspect that capturing the patient's view of change as a clinical outcome measure may not be as accurate as prospective measurements of QoL, the authors report that according to Fischer et al. [9], retrospective measures of QoL change have been found to be more sensitive to change than have serial measurements and may correlate more strongly with patients' overall satisfaction with the surgical intervention [19]. Another retrospective cross-sectional survey analysis of patients at least 1 year after undergoing adult tonsillectomy, which suggests that this procedure is of substantial benefit to adult patients in that it provides considerable symptom relief and QoL improvements, is the one conducted by Baumann et al. QoL measurements were conducted with the GBI and Specific Benefits from Tonsillectomy Inventory (SBTI). The SBTI is a modified, but not validated, version of the GBI, changed to measure specific symptom responses to tonsillectomy. Typical symptoms accompanying chronic tonsillitis are summarized under the scale 'symptom change'. The 'reduced use of resources' scale comprises items such as antibiotic use, doctor visits, sick leave and the impact from tonsillectomy on general health and QoL is assessed by the scale 'general benefit'. Significant improvements were demonstrated in three out of four GBI scores (total score, general health and physical functioning, all $\mathrm{p}<0.0001)$ and in all SBTI scores (symptom change, reduced use of resources and general benefit, all $\mathrm{p}<0.0001$ ). No significant benefit for the subscale 'social support' was noted $(\mathrm{p}=1)$, as in the study of Richards et al. This could be attributed, according to the authors, to cultural differences or possible translation idiosyncrasies. Length of follow-up and benefit score correlation in both inventories were not statistically significant ( $p>0.05$ ), findings that were in accordance with the above mentioned studies of Schwentner and Bhattacharyya. Gender also did not play a significant role in benefit evaluation, but younger patients ranked the impact of tonsillectomy in terms of benefit higher than older patients, something that was reflected in both inventories. Authors comment that maybe the somatic, functional, social, and emotional experience from chronic tonsillitis exerts a stronger influence on younger patients' estimates of their QoL than symptoms from other health problems. As in every study of this kind, phenomena of response shift, treatment placebo effects, satisfaction with medical care or medical providers as well as responder selection bias are potential limitations in interpreting the improvement after the intervention. Concerning these considerations the authors refer again to the observation that patients' retrospective views are still, and should always be an important parameter for the assessment of surgical satisfaction $[9,20]$. In an additional retrospective study by Oluwasanmi et al. findings also support the efficacy of tonsillectomy. 119 adult patients were surveyed regarding their symptoms in the 12 months preceding and following their tonsillectomy. Response rate was $55.5 \%$. There was a significant reduction in the incidence of sore throats, total number of days with a sore throat, amount of time taken off work or school, and number of visits to the general practitioner (all $\mathrm{p}<0.001$ ). More than 
half of the patients achieved complete resolution of all the measured parameters after tonsillectomy, while most of the remaining patients achieved at least $50 \%$ resolution. $95 \%$ of the patients found the operation effective in curing their sore throats and were glad they had had surgery. The authors notice that, as in every retrospective questionnaire, data should be interpreted with caution because of the inherent weaknesses of such studies [21].

A meta-analysis of randomised and non-randomised studies of the efficacy of adenotonsillectomy, by van Staaij et al., in children under 18 years of age, from 1963 to 2003, demonstrated a reduction in the frequency of sore throat episodes and upper respiratory tract infections with time, irrespective of surgery being performed or not. Tonsillectomy was shown only to result in a small reduction in frequency of sore throat episodes, days of sore throat associated school absences and upper respiratory tract infections, compared with 'watchful waiting'. Major limitations of this meta-analysis are that studies from the 1960s and 1970s had selection criteria for surgery that were likely to be significantly different than nowadays, cases were not categorised by symptom severity, and no adults were included [22]. A very recent review of the Cochrane Collaboration by Burton and Glasziou examined the efficacy of tonsillectomy or adeno-tonsillectomy versus nonsurgical treatment for chronic or recurrent acute tonsillitis. They included five randomised controlled studies, four undertaken with children (719 participants) and one with adults (70 participants). The study of adults by Alho et al. [23], as the only prospective, randomised and controlled trial in adults until now, recruited 70 adults, who had documented recurrent episodes of pharyngitis due to group A streptococcus, having had three or more episodes of pharyngitis in six months or four episodes in 12 months, and the episodes had to be severe enough for the patient to seek medical attention, and at least one episode had to be microbiologically proven by culture or rapid antigen test. Participants were randomised to either tonsillectomy or a period on a waiting list (control group). According to the review authors, this was an adequately randomised trial with appropriate allocation concealment. However, this study included only 'severely affected' adults, with one particular type of recurrent tonsillitis/pharyngitis, and looked at outcomes over a short follow up period (observations made after a follow-up of 90 days). So although at this period the tonsillectomy group had significantly less acute episodes of pharyngitis, significantly less mean number of days with fever or throat pain and needed significantly longer time for the occurrence of the first pharyngitis episode compared to the controls, the authors conclude that it is not possible to combine the data from this study with any others, nor to make direct comparisons between this and other studies. Furthermore, no good data are available on the medium to long-term effectiveness of tonsillectomy in adults. Adequate data are only available to evaluate the effects of surgery on severely affected children in the first postoperative year. Adeno-/tonsillectomy is effective in reducing the number of episodes of sore throat and days with sore throats in children, the gain being more marked in those most severely affected. The size of the effect is modest, whereas there is a slight benefit to knowing that the episode of a period of days with sore throat that follows surgery is entirely predictable (i.e. it occurs immediately after surgery as a direct consequence of it). Also some children get better without any surgery, as a consequence of the natural history of tonsillitis, and that whilst removing the tonsils will always prevent tonsillitis, the impact of the procedure on 'sore throats' due to pharyngitis is much less predictable. Thus the authors point out that it is of great importance to exactly define the role the palatine tonsils play in producing the clinical condition 'sore throat', because if these symptoms are independent of tonsillar infection, removing the tonsils may not have any effect [24].

In summary it can be stated that the efficacy of tonsillectomy in adults is of low evidence. Further prospective, randomised studies with appropriate nonsurgical control groups, with well defined criteria of chronic/recurrent tonsillitis, with an adequate study population and long follow ups, are needed. Thereby, conclusions can be drawn about the natural evolvement of the disease and potential methodological issues such as regression to mean, recall bias, or possible placebo effects can be minimized, thus enabling us to make safer evaluations about the efficacy of tonsillectomy.

Although, in regards to surgery for adults with chronic tonsillitis, tonsillectomy is established worldwide as the procedure of choice, an interesting study was performed by Ericsson et al., comparing, in a prospective randomised controlled trial, tonsillotomy using the radiofrequency technique with total blunt dissection tonsillectomy. Included were youths, 16-25 years old, who had obstructive symptoms and sore throat episodes in their case history. Tonsillotomy in young people was shown to be equivalent to traditional tonsillectomy in relieving symptoms in cases where the indication is infection in combination with airway obstruction of hypertrophied tonsils and this is the first study that suggest these results in this age group (former studies done only in children). Both methods resulted after 1 year in transition to normative levels on all dimensions of the SF-36, a measuring instrument assessing global QoL. In tonsillotomy patients recovery was significantly more rapid, the need for pain medication significantly decreased and the incidence of complications were lower compared with the tonsillectomy group. In the present study, primary and secondary hemorrhage only occurred in the tonsillectomy group. Additionally, tonsillotomy seems, according to provisional estimations, to be also more cost effective than tonsillectomy, if one also considers the cost of extra medication and of possible hemorrhage necessitating reoperation. A limitation of this study is that the number of infections was low in both groups, making it difficult to achieve the desired power to demonstrate significant statistical differences between them [25]. Further studies in adults, including older age groups, with recurrent symptoms but without obstructive problems, even though difficult to conduct, would give more evidence to this aspect.

\section{Postoperative Pain After Tonsillectomy}

Despite improvements in surgical and anaesthetic techniques, postoperative morbidity, mainly in the form of pain, remains a significant clinical problem. Postoperative pain is a very unpleasant experience for the patient and the impact on the QoL, even if short-dated, is substantial. According to the clinical experience, postoperative pain after 
Table 1. Reviewed Studies for the Efficacy of Tonsillectomy (TE) Including Adult Patients

\begin{tabular}{|c|c|c|c|}
\hline Authors & Type of Study & QoL Measuring Instrument and Results & Other Important Parameters \\
\hline Witsell et al. & $\begin{array}{l}\text { Multicenter } \\
\text { prospective } \\
\text { observational } \\
\text { outcomes study }\end{array}$ & $\begin{array}{l}\text { 1. modified TAHSI: } \\
\text { significant reduction in all } 6 \text { subscales } \\
(\mathrm{p}<0.0001) \\
\text { 2. SF-12: } \\
\text { a. PCS: } \\
\text { significant improvement at } 6 \text { months and } 1 \text { year } \\
(\mathrm{p}<0.0001) \\
\text { b. MCS: } \\
\text { significant improvement at } 6 \text { months } \\
(\mathrm{p}<0.0008) \text { but not after } 1 \text { year }(\mathrm{p}=0.55)\end{array}$ & $\begin{array}{l}\text { 1. number of sore throats } \\
\text { 2. days of work missed } \\
\text { 3. doctor visits for sore throats } \\
\text { 4. antibiotic usage } \\
\text { 5. halitosis : } \\
\text { in all reduction }(\mathrm{p}<0.0001)\end{array}$ \\
\hline $\begin{array}{l}\text { Koskenkorva } \\
\text { et al. }\end{array}$ & $\begin{array}{l}\text { prospective } \\
\text { cohort study }\end{array}$ & $\begin{array}{l}\text { GBI: } \\
\text { significant improvement in all subscales (p not } \\
\text { mentioned) }\end{array}$ & $\begin{array}{l}\text { Morbidity parameters between the least pleased patients, } \\
\text { according to the GBI, and the rest, pre- and post-TE, indicating } \\
\text { that the most important factor predicting patient satisfaction } \\
\text { after TE is the morbidity before the operation }\end{array}$ \\
\hline Akgun et al. & $\begin{array}{l}\text { retrospective } \\
\text { survey }\end{array}$ & None & $\begin{array}{l}\text { 1. days off work/school due to sore throat: reduced by } 95.3 \% \\
\text { 2. visits to the general practitioner(GP) due to sore throat: } \\
\text { reduced by } 95.6 \% \\
\text { 3. improvement in the feelings of well-being and general health } \\
\text { and in energy levels: in } 93 \% \\
\text { 4. days off work/school due to all other causes including } \\
\text { tonsillitis: reduced by } 84.4 \% \\
5 \text {. visits to the GP due to all causes including sore throats: } \\
\text { reduced by } 80.6 \%\end{array}$ \\
\hline Hsu et al. & $\begin{array}{l}\text { retrospective } \\
\text { study }\end{array}$ & None & $\begin{array}{l}\text { 1. mean frequency of tonsillitis per year } \\
\text { 2. mean duration in days of each episode of tonsillitis } \\
\text { 3. mean work days missed } \\
\text { 4. mean duration in days of poor food intake : } \\
\text { in all reduction }(\mathrm{p}<0.005)\end{array}$ \\
\hline Fujihara et al. & $\begin{array}{l}\text { retrospective } \\
\text { study }\end{array}$ & None & $\begin{array}{l}\text { 1. number of sore throat episodes with fever } \\
\text { 2. number of physician visits } \\
\text { 3. missed workdays : } \\
\text { in all reduction ( }<<0.0001 \text { for adults) }\end{array}$ \\
\hline Mui et al. & $\begin{array}{l}\text { retrospective } \\
\text { analysis }\end{array}$ & None & $\begin{array}{l}\text { 1. mean number of clinic visits for throat infection: } \\
\text { reduction }(\mathrm{p}<0.001) \\
\text { 2. mean number of prescriptions for oral antibiotics: } \\
\text { reduction ( } \mathrm{p}<0.001) \\
\text { 3. fewer sore throats: in } 88 \% \text { of patients } \\
\text { 4. less severe sore throats: in } 87 \% \\
\text { 5. fewer sick days off work or school: in } 90 \%\end{array}$ \\
\hline $\begin{array}{l}\text { Blair et al. } \\
\text { (Scottish } \\
\text { tonsillectomy } \\
\text { audit) }\end{array}$ & $\begin{array}{l}\text { retrospective } \\
\text { study }\end{array}$ & None & $\begin{array}{l}\text { Evaluation of satisfaction after TE: } 97 \% \text { were glad the } \\
\text { operation had been performed }\end{array}$ \\
\hline Kim et al. & $\begin{array}{l}\text { retrospective } \\
\text { survey }\end{array}$ & None & $\begin{array}{l}\text { 1. upper respiratory tract infections: improvement in } 87.4 \% \\
\text { 2. recurrent tonsillopharyngitis: improvement in } 89.4 \% \\
\text { 3. snoring: improvement in } 37 / 94 \text { patients } \\
\text { 4. loss of appetite: improvement in } 52 / 104 \\
\text { 5. easy fatigability: improvement in } 61 / 141 \\
\text { 6. cervical lymphadenitis: improvement in } 81 / 114 \\
\text { 7. mouth breathing: improvement in } 65 / 126 \\
\text { 8. foreign body sensation in the throat: improvement in } 60 / 102 \\
\text { 9. arthralgia: improvement in } 24 / 72\end{array}$ \\
\hline
\end{tabular}


(Table 1) contd....

\begin{tabular}{|c|c|c|c|}
\hline Authors & Type of Study & QoL Measuring Instrument and Results & Other Important Parameters \\
\hline $\begin{array}{l}\text { Schwentner et } \\
\text { al. }\end{array}$ & $\begin{array}{l}\text { retrospective } \\
\text { study }\end{array}$ & $\begin{array}{l}\text { GBI: } \\
\text { significant improvement } \\
\text { in all subscales, but more pronounced in the } \\
\text { general and physical health subscale than in the } \\
\text { social support subscale } \\
\text { (p not mentioned) }\end{array}$ & $\begin{array}{l}\text { 1. no difference in GBI scores in relation to follow-up time, } \\
\text { gender, TE technique } \\
\text { 2. significant difference in GBI subscores in patients with } \\
\text { coexistent chronic disease and/or other incriminatory events }\end{array}$ \\
\hline Richards et al. & $\begin{array}{l}\text { retrospective } \\
\text { survey }\end{array}$ & $\begin{array}{l}\text { GBI: } \\
\text { significant improvement }(\mathrm{p}<0.001) \text { in the total } \\
\text { score } \\
\text { and in all subscales, beside the social support } \\
\text { subscale }(\mathrm{p}>0.05)\end{array}$ & \\
\hline $\begin{array}{l}\text { Bhattacharyya } \\
\text { et al. }\end{array}$ & $\begin{array}{l}\text { cross-sectional } \\
\text { retrospective } \\
\text { survey analysis }\end{array}$ & $\begin{array}{l}\text { GBI: } \\
\text { significant improvement }(\mathrm{p}<0.001) \text { in total } \\
\text { score and in all subscales, but more pronounced } \\
\text { in the total score and general health subscore } \\
\text { than in the social and physical functioning } \\
\text { scores }\end{array}$ & $\begin{array}{l}\text { 1. number of weeks receiving antibiotics for sore throat } \\
\text { 2. number of workdays missed } \\
\text { 3. number of physician visits : } \\
\text { in all the above reduction }(\mathrm{p}<0.001) \\
\text { 4. no difference in GBI scores in relation to follow-up time }\end{array}$ \\
\hline $\begin{array}{l}\text { Baumann et } \\
\text { al. }\end{array}$ & $\begin{array}{l}\text { cross-sectional } \\
\text { retrospective } \\
\text { survey analysis }\end{array}$ & $\begin{array}{l}\text { 1. GBI: } \\
\text { significant improvement }(\mathrm{p}<0.0001) \text { in the total } \\
\text { score } \\
\text { and in all subscales, beside the social support } \\
\text { subscale }(\mathrm{p}=1) \\
\text { 2. SBTI: } \\
\text { significant improvement }(\mathrm{p}<0.0001) \text { in all } \\
\text { subscales }\end{array}$ & $\begin{array}{l}\text { 1. no difference in GBI and SBTI scores in relation to follow-up } \\
\text { time } \\
\text { 2. no difference in GBI and SBTI scores in relation to gender, } \\
\text { but younger patients ranked the impact of tonsillectomy in } \\
\text { terms of benefit higher than older patients }\end{array}$ \\
\hline $\begin{array}{l}\text { Oluwasanmi } \\
\text { et al. }\end{array}$ & $\begin{array}{l}\text { retrospective } \\
\text { study }\end{array}$ & None & $\begin{array}{l}\text { 1. incidence of sore throats } \\
\text { 2. total number of days with sore throat } \\
\text { 3. amount of time taken off work or school } \\
\text { 4. number of visits to the GP : } \\
\text { in the above all reduction ( }<<0.001 \text { ) } \\
5 .>50 \% \text { of the patients achieved complete resolution of all the } \\
\text { measured parameters after TE, while most of the remaining } \\
\text { patients achieved at least } 50 \% \text { resolution } \\
6.95 \% \text { of the patients found the operation effective in curing } \\
\text { their sore throats and were glad they had had surgery }\end{array}$ \\
\hline Alho et al. & $\begin{array}{l}\text { prospective } \\
\text { randomised } \\
\text { controlled trial }\end{array}$ & none & $\begin{array}{l}\text { 1. acute episodes of pharyngitis: reduction after } \mathrm{TE}(\mathrm{p}=0.001) \\
\text { 2. mean number of days with throat pain: reduction after } \mathrm{TE} \\
(\mathrm{p}=0.002) \\
\text { 3. mean number of days with fever: reduction after } \mathrm{TE}(\mathrm{p}=0.01)\end{array}$ \\
\hline Ericsson et al. & $\begin{array}{l}\text { prospective } \\
\text { randomised } \\
\text { controlled trial }\end{array}$ & $\begin{array}{l}\text { 1. SF-36: } \\
\text { significant improvement }(\mathrm{p}<0.001) \text { in all } \\
\text { subscales, beside the role emotional and mental } \\
\text { health subscale concerning the TE group and } \\
\text { significant improvement in all subscales, } \\
\text { beside the social functioning and role } \\
\text { emotional subscale in the tonsillotomy (TT) } \\
\text { group } \\
\text { 2. EQ VAS: } \\
\text { significant improvement in the TE and TT } \\
\text { groups }(\mathrm{p}<0.001)\end{array}$ & $\begin{array}{l}\text { 1. no significant difference between TT and TE groups in either } \\
\text { frequency or loudness of snoring } \\
\text { 2. no difference between TT and TE groups regarding upper } \\
\text { respiratory infections including sore throats or the use of } \\
\text { antibiotics } \\
\text { 3. Somewhat higher satisfaction score for the TE as compared } \\
\text { with for the TT group }(\mathrm{p}<0.05)\end{array}$ \\
\hline
\end{tabular}

tonsillectomy appears immediately after the operation and increases in intensity once again between the third and fifth postoperative day [2]. A wide variety of surgical and pharmacological methods has been described in an attempt to reduce pain after tonsillectomy, with conflicting results. The pain reliever must not increase bleeding and must have minimal side effects.

\section{2a. Non-Steroidal Anti-Inflammatory Drugs (NSAIDS)}

Recently NSAIDS have been shown to be effective in regulating pain after tonsillectomy. Regularly given postoperative pain treatment after tonsillectomy, starting intraoperatively, has shown significant advantages compared with a regimen on demand [26]. Compared with opioids, 
NSAIDs were found to be equianalgesic and the risk of emesis was significantly decreased [27].

Modern NSAIDs are now widely accepted analgesics for post-tonsillectomy patients, but their effect on secondary haemorrhage has not been fully evaluated. According to a literature review from Bowdlerv and Seeling, NSAIDS offer effective postoperative pain control, but may constitute a problem due to inhibition of platelet aggregation [28]. A meta-analysis comparing the incidence of postoperative hemorrhage with NSAIDs use after tonsillectomy showed that there is an increased risk of posttonsillectomy hemorrhage with the use of aspirin only after tonsillectomy; however, there appears to be no significant increased risk of bleeding for nonaspirin NSAIDs in this meta-analysis [29]. Smith and Wilde found in a retrospective analysis of 557 consecutive patients a significantly increased secondary haemorrhage rate in those taking regular NSAIDs, compared to those who did not. There was a higher rate of secondary haemorrhages with bipolar dissection than with standard dissection for both those taking and not taking NSAIDs, however this was not statistically significant. Both bipolar dissection and standard dissection individually showed very significant increases in secondary haemorrhage rate when on regular NSAIDs [30]. The evidence for nonsteroidal antiinflammatory drugs to increase the risk of bleeding after tonsillectomy is still equivocal [27]. That is why they should be prescribed with caution. The pyrazolone derivative, metamizol, may well prove to be of value for patients in whom the use of NSAIDS is contraindicated [28]. Two of the most commonly used NSAIDS are diclofenac and ibuprofen, which have been established for their good tolerance [31-33]. The selective COX-2 inhibitors seem to be very promising, concerning minimising gastrointestinal sideeffects and reducing bleeding complications through unaffected platelet aggregation. In a randomized, doubleblind, and placebo-controlled study with parallel groups Celecoxib, a COX-2 inhibitor, seemed to be more effective and safe than non-selective NSAIDs for pain management after discharge in patients with tonsillectomy [34].

\section{2b. Paracetamol}

Paracetamol is also a widely accepted analgesic, with distinctly lesser influence on platelet aggregation and gastrointestinal complications. It is also often used in combination with NSAIDs and/or opiates [35]. But compared to paracetamol, the use of NSAIDs showed no difference in pain relief and complication rates $[33,36]$.

\section{2c. Corticosteroids}

Corticosteroids are known for their antiemetic and analgesic potential. Studies until now have compared in a double-blinded, randomized, controlled manner the application of dexamethasone either as an i.v. single-shot dose, pre- or intraoperatively or in a continuous manner for the first seven to eight postoperative days. Results demonstrated a reduction to a different degree of postoperative pain and analgesic requirements after adult tonsillectomy [37-39] with the exception of one study, which reported no significant differences compared to placebo [40].

\section{2d. Antibiotics}

To the question of whether the routine use of systemic antibiotics is justified in adult tonsillectomy, a meta-analysis from 2008 of the Cochrane Collaboration illustrated that there is little or no evidence that perioperative antibiotics reduce pain, the need for analgesia, or secondary haemorrhage rates after tonsillectomy in children and adults, but they do however appear to reduce fever [41]. So their use is only justified in cases where there are signs and symptoms of a superinfection of the wound beds.

However, fusafungine, a locally applied antibiotic spray, showed, in an adjuvant setting to the standard postoperative analgesic therapy, to significantly reduce pain in the early days ( 2 - 4 day) after tonsillectomy and to improve wound healing [42].

\section{2e. Opiates}

Opiates are still widely used, despite unwanted sideeffects. In a study with peritonsillar infiltration with tramadol, a synthetic opioid, showed that it provided good intraoperative analgesia, less postoperative pain on awakening and lower analgesic requirement within the first hour after surgery [43]. However, nowadays, opiates, mainly in the form of tramadol, are largely used as combined therapy with non-steroidal anti-inflammatory drugs for patients with moderate to strong pain sensation [44].

\section{2f. Local Anaesthetic Drugs}

A systematic review of randomised controlled trials of adults and/or children undergoing tonsillectomy alone with local anaesthetic (a) injected into the tonsillar region immediately prior to removal of the tonsils, (b) injected into the tonsillar region after removal of the tonsils and (c) sprayed or otherwise applied to the tonsillar region after removal of the tonsils, brought no forward evidence that the use of perioperative local anaesthetics in patients undergoing tonsillectomy improves postoperative pain control. Because the trials identified were of small size and their effects may have been masked by co-administration of intravenous opiates, further randomised controlled trials are necessary [45]. Glossopharyngeal nerve block by means of local anaesthetics has in fact resulted in some children with severe upper airway obstruction and loss of protective reflexes, probably due to vagus nerve block, which is why great caution should be taken in such a procedure [46].

\section{2g. Alternative Pain-Relieving Measures and Other Factors}

In a recent controlled double-blinded study, the additional use of acupuncture to NSAIDs led to significant additional pain relief without having any additional sideeffects [47]. Gabapentin, an anticonvulsant, given pre- and postoperatively for 5 days, reduced opioid requirements in the first $24 \mathrm{~h}$ after tonsillectomy, but the benefits of the reduced opioid intake can be overshadowed by the drawbacks of side-effects (dizziness, gait disturbance and vomiting) [48]. Ketamine, a cyclohexanone derivative, infiltration into the tonsillar region after tonsillectomy was found to be easy and effective for the first 8 hours 
concerning analgesic needs [49], while the topical application of sucralfate, a basic amino salt of sucrose octasulfate, that binds to the matrix protein of peptic ulcers and produces a protective barrier, was found to significantly reduce throat pain and analgesic requirement after surgery [50]. Cryoanalgesia, in a randomized controlled trial, significantly reduced post-tonsillectomy pain without evidence of causing additional complications [51]. The transcutaneous electrostimulation (known especially in neurosurgery for the treatment of chronic pain syndromes) was harmless and effective in decreasing post-tonsillectomy pain in adults. A randomized comparison of three posttonsillectomy diets that included mainly rough food, mainly soft food, and no advice except to eat regularly, displayed no significant differences regarding post-operative morbidity. Therefore, specific post-tonsillectomy dietary advice need not be given, other than to encourage regular eating [52]. The addition of fibrin sealants to the tonsillar fossae, with and without lidocaine release, at the completion of tonsillectomy, could be considered a safe addition to patients who are not allergic to bovine products, because it reduces duration of intake of analgesics [53-55]. In a study of sealing the tonsillectomy field with posterior pillar mucosa (with mucosal palatopharyngeal arch flap) in pediatric tonsillectomy, significant reduction of pain after the third postoperative day and better healing when compared to a denuded site was observed. However, tissue edema is increased and considerations rise concerning traumatising important functional muscular units and superinfections due to the sutures in the mucosal flap [56]. The administration of muscle relaxants [57] as well as of hydrogen peroxide mouth rinses did not provide any better analgesic effects [58]. Further randomized, double blind, placebo-controlled studies are needed to investigate the efficacy of the abovementioned analgesic modalities. Laryngopharyngeal reflux is also an entity that could be associated with higher pain scores and significant decrease of wound healing after tonsillectomy [59]. In another study examining the effects of chewing gum in resuming normal diet after tonsillectomy, it was shown that it significantly delayed normal diet and increased the average amount of pain experienced over the controls [60].

\section{2h. Tonsillectomy Technique}

Concerning postoperative pain after tonsillectomy various studies have been conducted comparing cold tonsillectomy with various "hot" techniques, which are those that use thermal energy to cut and coagulate tissues, most of which demonstrate a prolonging of pain and return to normal diet with the hot techniques.

A systematic review of electrosurgery tonsillectomy in adults and children found that patients took approximately two days longer to return to a normal diet after diathermy, compared with cold steel dissection. Patients returned to a normal diet after a similar or a shorter time with coblation compared to diathermy. A limitation of some of the included studies was an unclear report of the treatment allocation methods, or the failure to use outcome assessors that were blinded to treatment allocation. Inadequate reporting also took place in the non-randomized comparative studies [61]. In another systematic review of the literature comparing electrodissection versus cold knife dissection on posttonsillectomy pain, electrodissection also increased pain in comparison to sharp dissection for tonsillectomy [16]. In a publication of Thomaser et al., pain following tonsillectomy was related to the amount of intraoperatively applied coagulation current, especially in the late postoperative course (days 10 - 14). This might be explained by tissue damage and increased eschar formation due to coagulation [62].

Coblation tonsillectomy is a relative new "hot" technique, which is a variation of bipolar electrosurgery in terms of generating lower temperatures $\left(40^{\circ} \mathrm{C}\right.$ to $\left.70^{\circ} \mathrm{C}\right)$ thus minimizing thermal damage to surrounding tissues [63] and claims shorter operating time, minimal intra-operative blood loss, and a suitable cost, with no additional increase in postoperative pain and hemorrhage. In this respect, a review of the literature by Windfuhr showed conflicting results that range from rejection to recommendation of this type of tonsillectomy [64].

Argon plasma coagulation (APC) is a monopolar form of coblation. This non-contact technique uses a stream of ionized argon as medium for the electrical current [63], which offers effective hemostasis and limited penetration depth of the coagulation beam [65]. In three prospective randomised controlled trials comparing APC to cold-steel dissection there was no statistically significant difference between the two methods in the intensity of postoperative pain [65-67].

Concerning these new "hot" techniques, larger and better-conducted studies are necessary in order to determine their safety and efficacy.

A prospective, randomized, controlled clinical study comparing thermal welding, a new technique that uses the simultaneous application of heat and pressure to cut and coagulate tissue [63], versus cold dissection tonsillectomy in adults, demonstrated statistically significant lower pain scores from the first to the fourth postoperative days and cessation of significant pain 3 days earlier than in the cold dissection group $(\mathrm{p}<0.05)$, but no significant difference was observed regarding pain medication [68]. In another randomised prospective study of thermal welding versus bipolar electrocautery tonsillectomy, mean postoperative pain scores and mean time for return to normal diet were also significantly lower in the thermal welding group [69].

One systematic review found five randomised and four non-randomized comparative studies about the use of the harmonic scalpel in children and adults. This technique uses a blade that vibrates at $55.5 \mathrm{kHz}(55,500$ cycles per second $)$ over a distance of $80 \mu \mathrm{m}$ to cut tissue, thus generating heat in the tissue (between $50^{\circ} \mathrm{C}$ and $100^{\circ} \mathrm{C}$ ) which coagulates the blood vessels [63]. The pain scores less than 7 days after surgery were comparable in the ultrasonic scalpel tonsillectomy, diathermy, and cold-steel dissection, but two weeks after surgery the pain was significantly worse after the ultrasonic-scalpel technique, compared with cold-steel dissection, but was better compared with diathermy. The time that it took for patients who had ultrasonic-scalpel tonsillectomy to return to a normal diet or appetite was similar or shorter, compared with cold-steel dissection or diathermy. But the evidence base for this procedure was small, and generally of a low quality [70]. 
As to the laser techniques of hot tonsillectomy, the carbon dioxide laser, potassium titanyl phosphate (KTP) laser, and contact diode laser are the most commonly used, whereby energy is delivered through a flexible optical fibre, used as a scalpel to dissect and coagulate tissues [63]. In a systematic review, which included four randomised controlled trials, two non-randomized comparative studies, and one case series of laser tonsillectomy in adults and children, the pain in the first postoperative day was lower after laser tonsillectomy than after cold-steel dissection, but was subsequently greater until 2 weeks postoperatively. One study found that pain was consistently lower in the contactdiode laser group compared with the diathermy group [71].

\section{Post-Tonsillectomy Hemorrhage (PTH)}

The occurrence of PTH is always a negative factor for the outcome of tonsillectomy, influencing QoL mostly in the immediate postoperative period. This complication can, however, vary from a harmless, self-limiting event without any sequelae for the patient, to an incidence that needs hospital readmission, blood transfusion, or further surgery to arrest ongoing haemorrhage. In the latter case, beside the additional psychological burden for the patient, another therapeutic intervention always accompanies the possibility of further complications, some of which can also leave permanent deficits for the patients, thus developing permanent impairments in their QoL. Fatal outcomes have also been reported, however very rare $(0.007 \%)$ [72]. Primary post-tonsillectomy bleeding occurs during the first 24 hours following the procedure as a consequence of inadequate suturing/ligation of the feeding arteries. Secondary post-tonsillectomy bleeding occurs most frequently between the $5^{\text {th }}$ and $10^{\text {th }}$ postoperative day [73]. The Prospective National Audit, an investigation of the occurrence of postoperative hemorrhage after tonsillectomy between July 2003 and September 2004, with electronic web-based data collection from the National Health Service and independent hospitals in England and Northern Ireland, demonstrated an occurrence of $0.6 \%$ for primary hemorrhage and $3 \%$ for secondary hemorrhage [74], while a national study using data from the Norwegian Patient Registry from 1999 to 2005 showed a mean rebleeding rate of $0.5 \%$ [75]. The incidence of overall PTH has been reported to be as high as $18-20 \%$ [76]. As in the case of the postoperative pain after tonsillectomy, a wide range of medical applications, surgical techniques as well as factors that could influence PTH rates, has been discussed in the literature. The effect of NSAIDs has already been illustrated in paragraph $2 \mathrm{a}$.

\section{3a. Antibiotics}

Although in a prospective study by Stephens et al. a relationship was found between bacterial colonisation of the tonsillar fossa and PTH [77], a systematic review of the electronic databases Medline, Embase, and Cochrane Controlled Trials Register by Dhiwakar et al. showed no significant difference in the incidence of significant and total hemorrhage, in children or adults undergoing tonsillectomy or adenotonsillectomy, to whom antibiotics were administered intraoperatively and/or postoperatively, while further trials are needed to better define their role in the occurrence of this complication [78].

\section{3b. Coagulopathies}

A meta-analysis from Krishna et al. demonstrated a lacking effect of laboratory tests to predict postoperative bleeding complications [79]. Thus a careful history of bleeding risks and testing initially only patients with suspicious history, as a further extensive preoperative haematological screening is not budget-friendly [80], reduces the risk of PTH more effectively [81]. On the other hand, normal coagulation values and an insignificant history do not rule out coagulation disorders. If diffuse, persistent, and bilateral bleeding is not related to arterial hypertension, dissection technique, or local infection, a prompt and detailed coagulation screening should be considered [82].

\section{3c. Meteorological Conditions}

The influence of meteorological conditions on PTH is arguable. In a retrospective study of 256,799 tonsillectomies in NHS trusts in England, there was a bimodal seasonal distribution peaking in the winter and summer months [83], while in another retrospective study a statistically significant increase in the incidence of primary PTH was noticed, when cyclonic conditions prevailed [84]. In another prospective study, it is suggested that tonsillectomy performed in warmer weather, when the water vapour pressure is higher, may reduce the secondary PTH rate [85]. This is clearly a multifactorial problem and further studies are needed to delineate such correlations. However, in patients at high risk of bleeding, consideration could be given to performing tonsillectomy at a time of year of lower incidence.

\section{3d. Analgesia}

Two studies that dealt with the question, whether an inadequate analgesic prescription increases secondary $\mathrm{PTH}$ rates, gave conflicting results, hence suggesting that additional research of a possible relationship is needed. In a completed audit loop, an adequate analgesia showed to be essential in order to keep the secondary haemorrhage rate within an acceptable range [86], while in another retrospective review the post-tonsillectomy readmission rate was not affected by the duration of postoperative analgesia [87].

\section{3e. Local and General Anaesthesia}

The method of anaesthesia in tonsillectomy also seems to have an influence on the PTH rate. In a prospective study 1063 patients were evaluated, whereby PTH occurred after local anaesthesia more frequently than under general anaesthesia $(4.12 \%$ vs $7.55 \%$ : $\mathrm{p}<0.001 \%)$. Primary PTH also occurred more frequently after local anaesthesia, but under this method there was no secondary PTH after the $6^{\text {th }}$ postoperative day, whereas under general anaesthesia $44 \%$ of the PTH took place after the $6^{\text {th }}$ postoperative day [88].

\section{3f. Age, Gender, History of Symptoms, Histology and Other Factors}

Various studies conclude that adults, patients of older age (especially 70 years or older), male patients, a history of chronic tonsillitis and/or of recurrent tonsillitis, a histology of cryptic tonsillitis, excessive intraoperative blood loss and elevated postoperative mean arterial pressure and anemia (especially in women) are significant risk factors for PTH. 
Being aware of these risk factors could help identify patients with postoperative bleeding potential [72, 89-93]. Also repeated episodes of bleeding should be considered as a warning sign of serious PTH, defined as such that is accompanied by hemorrhagic shock, requiring resuscitation and/or major medical treatment with possible lethal outcome $[89,94]$. The use of fibrin glue for coating the tonsillar beds after tonsillectomy did not demonstrate in a prospective, randomized, double-blind trial any statistically significant difference of PTH compared to that of the controls [95]. Superstition, for example, as to whether PTH occurs more frequently in redheaded children, in patterns of threes, on Friday-the-13th days, or with the full moon was also shown not to play a role in the rates of PTH [96]. The age and concomitant experience of surgeons in terms of a greater incidence of haemorrhage in tonsillectomies conducted by more junior surgeons, can influence this outcome [97].

\section{3g. Tonsillectomy Technique}

"Hot" tonsillectomy techniques are becoming increasingly popular in an effort to reduce operative time and intraoperative bleeding [63]. According to Hilton and a Cochrane review, the difference in operating time is no more than a few minutes, having minimal potential in altering the flow-rate of cases on a standard operating list, and the intraoperative haemorrhage has been shown to have been about $30 \mathrm{~mL}$ per patient, when comparing cold dissection with diathermy dissection $[73,98]$. This amount is only $3 \%$ of the circulating blood volume of a 2-year-old child, while most tonsillectomies are done on older children and adults. So he summarizes that it is difficult to argue that diathermy in tonsillectomy confers significant benefit in most patients [73]. In the Prospective National Audit of England and Northern Ireland, an elevated PTH rate was observed in tonsillectomies performed using diathermy for dissection and hemostasis compared with cold steel dissection and ties for hemostasis. These results suggest that "hot" tonsillectomy techniques carry a significantly higher risk of PTH when diathermy is used in tonsillectomy [74]. A systematic review from Mowatt et al. analyzed data from 50 primary studies, and three population-based registry reports. Their metaanalysis showed that bipolar diathermy had lower rates of primary hemorrhage, compared to cold-steel dissection with packs or ties. But the rate of secondary hemorrhage after "hot" techniques (diathermy, coblation, and cold-steel dissection with diathermy) was higher compared with coldsteel dissection [61, 63]. A possible explanation could be that cauterization sometimes combined with the additional use of intraoperative vasoconstrictors can be associated with an increased temporal and spatial application of coagulating current. Although this technique is very effective in preventing primary hemorrhage, it does result in a deeper and more extensive zone of necrosis, which leads to the exposure of more and larger vessels when sloughing of the eschar occurs [99]. On the other hand, another systematic review of prospective trials comparing monopolar electrocautery versus cold knife dissection tonsillectomy displayed no significantly different PTH rates when comparing the two methods [16].

As mentioned above in paragraph $2 \mathrm{~h}$., according to another systematic review of the literature by Windfuhr, definite conclusions about coblation tonsillectomy cannot be drawn [64], although histopathologic results have shown less thermal injury than monopolar electrosurgery techniques [100].

The APC tonsillectomy technique has demonstrated, according to the results of two prospective randomised controlled studies, a significant reduction of intraoperative blood loss and no significant difference in primary and secondary PTH rates compared to cold-steel dissection [65, $66]$.

In a randomized controlled study assessing PTH of thermal welding compared to cold dissection, no significant difference was observed [68], whereas in another randomised prospective study the primary and secondary PTH was lower in the thermal welding group compared to a bipolar electrocautery tonsillectomy group [69].

Concerning the harmonic scalpel tonsillectomy, a systematic review of the literature of Neumann et al., including eleven randomized controlled trials, of which five comparing harmonic scalpel tonsillectomy with "cold steel" tonsillectomy and six comparing harmonic scalpel with "hot" tonsillectomy techniques, demonstrated a low quality evidence, which does not support any significant difference in PTH rates when harmonic scalpel is compared with other tonsillectomy techniques [101].

In the systematic review mentioned in paragraph $2 \mathrm{~h}$, which included studies comparing laser techniques for tonsillectomy with cold dissection, three studies found that wound healing was slower after laser tonsillectomy, compared with cold-steel dissection. The mean intraoperative blood loss was lower with KTP-laser, compared with cold-steel dissection, but there was a slight increase in PTH rates. Of notice, is that some studies used other methods to control bleeding $[63,71]$.

As mentioned earlier further studies are needed in order to compare the safety of these new "hot" techniques against conventional tonsillectomy methods.

Lastly the type of instrumentation may also play a role in PTH rates. In a retrospective analysis of 13,593 procedures in Wales a significant rise in postoperative primary haemorrhage, but not secondary haemorrhage, was seen following the introduction of single-use instruments, compared to that observed with reusable instruments, which reverted again to baseline with the introduction of specified single-use instruments [102].

\section{Cost-Effectiveness of Tonsillectomy as Another Factor of QoL}

The question of if tonsillectomy compared to medical therapy for chronic tonsillitis could prove itself as costeffective for the patient is a new aspect arising in the current days of cost-containment for counselling to the patients, as economic factors could in many ways, and not only indirectly, influence global and disease specific QoL, for example in the case of postponement of a clinically indicated procedure due to financial difficulties. Therefore they should always be considered in order to determine the true benefit of this surgical intervention. As mentioned in the paragraphs above, tonsillectomy significantly reduces the number of physician visits, the duration of intake of antibiotics and work days missed, all of which are costly factors. 
Bhattacharyya and Kepnes were the first to address the economic benefit of tonsillectomy in adults with chronic tonsillitis, by using a break-even time analysis. Thereby, the point in time at which the up front-cost of the surgical intervention is recovered by the decreased health-care costs and increased productivity due to fewer work days missed after the procedure in the subsequent years after the intervention can be determined. In their retrospective study, for the two 12-month periods before and after tonsillectomy, they assessed a break-even point for net cost savings of 12.7 years and for the overall economic costs of 2.3 years, thus presenting tonsillectomy as an "investment" toward anticipated improvements in health status [103]. Fujihara et al. also performed a break-even time analysis in Japan and found in adults a break-even point for net savings of 5.2 years and for the overall economic costs of 2.5 years, showing that tonsillectomy is also cost-effective [12].

\section{CONCLUSION}

The effects on QoL in adult patients with chronic tonsillitis are multifactorial. The main therapeutic measure to help improve the global and disease specific QoL of these patients is, according to current standards, the tonsillectomy. The evidence of the efficiency of this procedure is however not of a high level and further studies need to fortify its application. Two of the many additional factors which play an essential role in the positive outcome of tonsillectomy, and consequently in the overall improvement of QoL of these patients, is the management of the postoperative pain and the diminishment of the possibilities for a PTH. Many medical and interventional methods have been proposed concerning ameliorating these parameters, but otolaryngologists must make careful choices between them, as many of these methods should be further investigated. In recent years the cost-effectiveness of tonsillectomy is becoming an increasingly important aspect in counselling patients with chronic tonsillitis, as the economic factor can have not only indirect but also direct effects on their QoL.

\section{REFERENCES}

[1] Schwentner I, Hofer S, Schmutzhard J, Deibl M, Sprinzl GM. Impact of tonsillectomy on quality of life in adults with chronic tonsillitis. Swiss Med Wkly 2007 11; 137(31-32): 454-61.

[2] Baumann I. Outcome after tonsillectomy for chronic tonsillitis. HNO 2005; 53(5): 405-7.

[3] Cella DF, Bonomi AE. Measuring quality of life: 1995 update. Oncology (Williston Park) 1995; 9(11 Suppl): 47-60.

[4] Stewart MG. Outcomes research: an overview. ORL J Otorhinolaryngol Relat Spec 2004; 66(4): 163-6.

[5] Paradise JL, Bluestone CD, Bachman RZ, et al. Efficacy of tonsillectomy for recurrent throat infection in severely affected children. Results of parallel randomized and nonrandomized clinical trials. N Engl J Med 1984 15; 310(11): 674-83.

[6] Witsell DL, Orvidas LJ, Stewart MG, et al. Quality of life after tonsillectomy in adults with recurrent or chronic tonsillitis. Otolaryngol Head Neck Surg 2008; 138(1 Suppl): S1-8.

[7] Robinson K, Gatehouse S, Browning GG. Measuring patient benefit from otorhinolaryngological surgery and therapy. Ann Otol Rhinol Laryngol 1996; 105(6): 415-22.

[8] Koskenkorva T, Koivunen P, Penna T, Teppo H, Alho OP. Factors affecting quality-of-life impact of adult tonsillectomy. J Laryngol Otol 2009; 123(9): 1010-4.

[9] Fischer D, Stewart AL, Bloch DA, Lorig K, Laurent D, Holman H. Capturing the patient's view of change as a clinical outcome measure. JAMA 1999 22-29; 282(12): 1157-62.
[10] Akgun D, Seymour FK, Qayyum A, Crystal R, Frosh A. Assessment of clinical improvement and quality of life before and after tonsillectomy. J Laryngol Otol 2009; 123(2): 199-202.

[11] Hsu AP, Tan KL, Tan YB, Han HJ, Lu PK. Benefits and efficacy of tonsillectomy for recurrent tonsillitis in adults. Acta Otolaryngol 2007; 127(1): 62-4.

[12] Fujihara K, Koltai PJ, Hayashi M, Tamura S, Yamanaka N. Costeffectiveness of tonsillectomy for recurrent acute tonsillitis. Ann Otol Rhinol Laryngol 2006; 115(5): 365-9.

[13] Mui S, Rasgon BM, Hilsinger RL, Jr. Efficacy of tonsillectomy for recurrent throat infection in adults. Laryngoscope 1998; 108(9): 1325-8.

[14] Blair RL, McKerrow WS, Carter NW, Fenton A. The Scottish tonsillectomy audit. The Audit Sub-Committee of the Scottish Otolaryngological Society. J Laryngol Otol Suppl 1996; 20: 1-25.

[15] Kim JY, Lee CH. Clinical study on the efficacy of tonsilloadenoidectomy. Acta Otolaryngol Suppl 1988; 454: 265-72.

[16] Leinbach RF, Markwell SJ, Colliver JA, Lin SY. Hot versus cold tonsillectomy: a systematic review of the literature. Otolaryngol Head Neck Surg 2003; 129(4): 360-4.

[17] Sprangers MA, Schwartz CE. Integrating response shift into healthrelated quality of life research: a theoretical model. Soc Sci Med 1999; 48(11): 1507-15.

[18] Richards AL, Bailey M, Hooper R, Thomson P. Quality-of-life effect of tonsillectomy in a young adult group. A N Z J Surg 2007; 77(11): 988-90.

[19] Bhattacharyya N, Kepnes LJ, Shapiro J. Efficacy and quality-oflife impact of adult tonsillectomy. Arch Otolaryngol Head Neck Surg 2001; 127(11): 1347-50.

[20] Baumann I, Kucheida H, Blumenstock G, Zalaman IM, Maassen MM, Plinkert PK. Benefit from tonsillectomy in adult patients with chronic tonsillitis. Eur Arch Otorhinolaryngol 2006; 263(6): 556-9.

[21] Oluwasanmi AF, Thornton MR, Khalil HS, Tierney PA. Effect of tonsillectomy on recurrent sore throats in adults: patients' perspectives. J Laryngol Otol 2006; 120(2): e7.

[22] van Staaij BK, van den Akker EH, van der Heijden GJ, Schilder AG, Hoes AW. Adenotonsillectomy for upper respiratory infections: evidence based? Arch Dis Child 2005; 90(1): 19-25.

[23] Alho OP, Koivunen P, Penna T, Teppo H, Koskela M, Luotonen J. Tonsillectomy versus watchful waiting in recurrent streptococcal pharyngitis in adults: randomised controlled trial. BMJ 2007 5; 334(7600): 939.

[24] Burton MJ, Glasziou PP. Tonsillectomy or adeno-tonsillectomy versus non-surgical treatment for chronic/recurrent acute tonsillitis. Cochrane Database Syst Rev 2009(1): CD001802.

[25] Ericsson E, Ledin T, Hultcrantz E. Long-term improvement of quality of life as a result of tonsillotomy (with radiofrequency technique) and tonsillectomy in youths. Laryngoscope 2007; 117(7): 1272-9.

[26] Thorneman G, Akervall J. Pain treatment after tonsillectomy: advantages of analgesics regularly given compared with analgesics on demand. Acta Otolaryngol 2000; 120(8): 986-9.

[27] Moiniche S, Romsing J, Dahl JB, Tramer MR. Nonsteroidal antiinflammatory drugs and the risk of operative site bleeding after tonsillectomy: a quantitative systematic review. Anesth Analg 2003; 96(1): 68-77, table of contents.

[28] Bowdler IM, Seeling W. The role of non-opioid analgesics in the management of postoperative pain. Schmerz 1993; 7(2): 97-106.

[29] Krishna S, Hughes LF, Lin SY. Postoperative hemorrhage with nonsteroidal anti-inflammatory drug use after tonsillectomy: a meta-analysis. Arch Otolaryngol Head Neck Surg 2003; 129(10): 1086-9.

[30] Smith I, Wilde A. Secondary tonsillectomy haemorrhage and nonsteroidal anti-inflammatory drugs. J Laryngol Otol 1999; 113(1): 28-30.

[31] Nordbladh I, Ohlander B, Bjorkman R. Analgesia in tonsillectomy: a double-blind study on pre and post-operative treatment with diclofenac. Clin Otolaryngol Allied Sci 1991; 16(6): 554-8.

[32] Tawalbeh MI, Nawasreh OO, Husban AM. Comparative study of diclofenac sodium and paracetamol for treatment of pain after adenotonsillectomy in children. Saudi Med J 2001; 22(2): 121-3.

[33] St Charles CS, Matt BH, Hamilton MM, Katz BP. A comparison of ibuprofen versus acetaminophen with codeine in the young tonsillectomy patient. Otolaryngol Head Neck Surg 1997; 117(1): 76-82. 
[34] Nikanne E, Kokki H, Salo J, Linna TJ. Celecoxib and ketoprofen for pain management during tonsillectomy: a placebo-controlled clinical trial. Otolaryngol Head Neck Surg 2005; 132(2): 287-94.

[35] White MC, Nolan JA. An evaluation of pain and postoperative nausea and vomiting following the introduction of guidelines for tonsillectomy. Paediatr Anaesth 2005; 15(8): 683-8.

[36] Hiller A, Silvanto M, Savolainen S, Tarkkila P. Propacetamol and diclofenac alone and in combination for analgesia after elective tonsillectomy. Acta Anaesthesiol Scand 2004; 48(9): 1185-9.

[37] McKean S, Kochilas X, Kelleher R, Dockery M. Use of intravenous steroids at induction of anaesthesia for adult tonsillectomy to reduce post-operative nausea and vomiting and pain: a double-blind randomized controlled trial. Clin Otolaryngol 2006; 31(1): 36-40.

[38] Stewart R, Bill R, Ullah R, McConaghy P, Hall SJ. Dexamethasone reduces pain after tonsillectomy in adults. Clin Otolaryngol Allied Sci $2002 ; 27(5)$ : 321-6.

[39] Carr MM, Williams JG, Carmichael L, Nasser JG. Effect of steroids on posttonsillectomy pain in adults. Arch Otolaryngol Head Neck Surg 1999; 125(12): 1361-4.

[40] Lachance M, Lacroix Y, Audet N, Savard P, Thuot F. The use of dexamethasone to reduce pain after tonsillectomy in adults: a double-blind prospective randomized trial. Laryngoscope 2008; 118(2): 232-6.

[41] Dhiwakar M, Clement WA, Supriya M, McKerrow WS. Antibiotics to reduce post-tonsillectomy morbidity. Cochrane Database Syst Rev 2008(2): CD005607.

[42] Lukan N. Fusafungine after tonsillectomy. Laryngorhinootologie 2002; 81(6): 426-9.

[43] Ugur MB, Yilmaz M, Altunkaya H, Cinar F, Ozer Y, Beder L. Effects of intramuscular and peritonsillar injection of tramadol before tonsillectomy: a double blind, randomized, placebocontrolled clinical trial. Int J Pediatr Otorhinolaryngol 2008; 72(2): 241-8.

[44] Metternich FU, Brusis T, Parandeh-Shab F. Pain therapy after tonsillectomy in adults. HNO 1998; 46(1): 50-5.

[45] Hollis LJ, Burton MJ, Millar JM. Perioperative local anaesthesia for reducing pain following tonsillectomy. Cochrane Database Syst Rev 2000(2): CD001874.

[46] Bean-Lijewski JD. Glossopharyngeal nerve block for pain relief after pediatric tonsillectomy: retrospective analysis and two cases of life-threatening upper airway obstruction from an interrupted trial. Anesth Analg 1997; 84(6): 1232-8.

[47] Sertel S, Herrmann S, Greten HJ, et al. Additional use of acupuncture to NSAID effectively reduces post-tonsillectomy pain. Eur Arch Otorhinolaryngol 2009; 266(6): 919-25.

[48] Mikkelsen S, Hilsted KL, Andersen PJ, et al. The effect of gabapentin on post-operative pain following tonsillectomy in adults. Acta Anaesthesiol Scand 2006; 50(7): 809-15.

[49] Erhan OL, Goksu H, Alpay C, Bestas A. Ketamine in posttonsillectomy pain. Int $\mathrm{J}$ Pediatr Otorhinolaryngol 2007; 71(5): 735-9.

[50] Ozcan M, Altuntas A, Unal A, Nalca Y, Aslan A. Sucralfate for posttonsillectomy analgesia. Otolaryngol Head Neck Surg 1998; 119(6): 700-4.

[51] Robinson SR, Purdie GL. Reducing post-tonsillectomy pain with cryoanalgesia: a randomized controlled trial. Laryngoscope 2000; 110(7): 1128-31.

[52] Cook JA, Murrant NJ, Evans KL, Lavelle RJ. A randomized comparison of three post-tonsillectomy diets. Clin Otolaryngol Allied Sci 1992; 17(1): 28-31

[53] Vaiman M, Krakovski D, Gavriel H. Fibrin sealant reduces pain after tonsillectomy: prospective randomized study. Ann Otol Rhinol Laryngol 2006; 115(7): 483-9.

[54] Stevens MH, Stevens DC. Pain reduction by fibrin sealant in older children and adult tonsillectomy. Laryngoscope 2005; 115(6): 1093-6.

[55] Kitajiri S, Tabuchi K, Hiraumi H, Kaetsu H. Relief of posttonsillectomy pain by release of lidocaine from fibrin glue. Laryngoscope 2001 ; 111(4 Pt 1): 642-4.

[56] Genc E, Hanci D, Ergin NT, Dal T. Can mucosal sealing reduce tonsillectomy pain? Int J Pediatr Otorhinolaryngol 2006; 70(4): 725-30.

[57] Lunghi F, Caligo G, Di Franco R, et al. The randomized doubleblind study of postoperative tonsillectomy pain control by muscle relaxants. Acta Otorhinolaryngol Ital 1993; 13(4): 355-63.
[58] Chacra ZA, Manoukian JJ, Al-Qahtani K, et al. Hydrogen peroxide mouth rinse: an analgesic post-tonsillectomy. J Otolaryngol 2005; 34(3): 178-82.

[59] Elwany S, Nour YA, Magdy EA. Does laryngopharyngeal reflux affect healing and recovery after tonsillectomy? J Laryngol Otol 2008; 122(6): 603-8.

[60] Hanif J, Frosh A. Effect of chewing gum on recovery after tonsillectomy. Auris Nasus Larynx 1999; 26(1): 65-8.

[61] Mowatt G CJ, Fraser C, Burr J. Systematic review of the safety and efficacy of electrosurgery for tonsillectomy. 2005 Date: Available from: http: //www.nice.org.uk/download.aspx?o=ip Vं324review.

[62] Thomaser EG, Tschopp K. Influence of intraoperatively applied current of coagulation on the postoperative course in tonsillectomy. Laryngorhinootologie 2004; 83(8): 501-6.

[63] Scott A. Hot techniques for tonsillectomy. Issues Emerg Health Technol 2006 (93): 1-6.

[64] Windfuhr JP. Coblation tonsillectomy: a review of the literature. HNO 2007; 55(5): 337-48.

[65] Ferri E, Armato E, Capuzzo P. Argon plasma coagulation versus cold dissection tonsillectomy in adults: a clinical prospective randomized study. Am J Otolaryngol 2007; 28(6): 384-7.

[66] Bergler W, Huber K, Hammerschmitt N, Hormann $K$. Tonsillectomy with argon plasma coagulation (APC): evaluation of pain and hemorrhage. Laryngoscope 2001; 111(8): 1423-9.

[67] Skinner LJ, Colreavy MP, Lang E, O'Hare B, Charles DA, Timon CI. Randomized controlled trial comparing argon plasma coagulation tonsillectomy with conventional techniques. J Laryngol Otol 2003; 117(4): 298-301.

[68] Stavroulaki P, Skoulakis C, Theos E, Kokalis N, Valagianis D. Thermal welding versus cold dissection tonsillectomy: a prospective, randomized, single-blind study in adult patients. Ann Otol Rhinol Laryngol 2007; 116(8): 565-70.

[69] Karatzias GT, Lachanas VA, Sandris VG. Thermal welding versus bipolar tonsillectomy: a comparative study. Otolaryngol Head Neck Surg 2006; 134(6): 975-8.

[70] Interventional procedures overview of tonsillectomy using ultrasonic scalpel. 2006 Date: Available from: http://www.nice. org.uk/download.aspx?o=ip242overview.

[71] Interventional procedure overview of tonsillectomy using laser. 2006 Date: Available from: http://www.nice.org.uk/download. aspx?o=ip057overview.

[72] Windfuhr JP, Chen YS. Post-tonsillectomy and -adenoidectomy hemorrhage in nonselected patients. Ann Otol Rhinol Laryngol 2003; 112(1): 63-70.

[73] Hilton M. Tonsillectomy technique--tradition versus technology. Lancet 2004 21-27; 364(9435): 642-3.

[74] Lowe D, van der Meulen J, Cromwell D, et al. Key messages from the National Prospective Tonsillectomy Audit. Laryngoscope 2007; 117(4): 717-24.

[75] Kvaerner KJ. Benchmarking surgery: secondary post-tonsillectomy hemorrhage 1999-2005. Acta Otolaryngol 2009; 129(2): 195-8.

[76] Blakley BW. Post-tonsillectomy bleeding: how much is too much? Otolaryngol Head Neck Surg 2009; 140(3): 288-90.

[77] Stephens JC, Georgalas C, Kyi M, Ghufoor K. Is bacterial colonisation of the tonsillar fossa a factor in post-tonsillectomy haemorrhage? J Laryngol Otol 2008; 122(4): 383-7.

[78] Dhiwakar M, Eng CY, Selvaraj S, McKerrow WS. Antibiotics to improve recovery following tonsillectomy: a systematic review. Otolaryngol Head Neck Surg 2006; 134(3): 357-64.

[79] Krishna P, Lee D. Post-tonsillectomy bleeding: a meta-analysis. Laryngoscope 2001; 111(8): 1358-61.

[80] Gerlinger I, Torok L, Nagy A, Patzko A, Losonczy H, Pytel J. Frequency of coagulopathies in cases with post-tonsillectomy bleeding. Orv Hetil 2008 9; 149(10): 441-6.

[81] Eberl W, Wendt I, Schroeder HG. Preoperative coagulation screening prior to adenoidectomy and tonsillectomy. Klin Padiatr 2005; 217(1): 20-4.

[82] Windfuhr JP, Chen YS, Remmert S. Unidentified coagulation disorders in post-tonsillectomy hemorrhage. Ear Nose Throat J 2004; 83(1): 28, 30, 2 passim.

[83] Chadha NK. Tonsillectomy return-to-theatre rates demonstrate a monthly and seasonal variation: an analysis of 256,799 patients. $\mathrm{J}$ Laryngol Otol 2007; 121(11): 1088-93.

[84] Racic G, Kurtovic D, Colovic Z, Dogas Z, Kardum G, Roje Z. Influence of meteorological conditions on post-tonsillectomy haemorrhage. J Laryngol Otol 2008; 122(12): 1330-4. 
[85] Lee MS, Montague ML, Hussain SS. The influence of weather on the frequency of secondary post-tonsillectomy haemorrhage. J Laryngol Otol 2005; 119(11): 894-8.

[86] Alhamarneh O, Raja H, England RJ. Inadequate analgesic prescription increases secondary post-tonsillectomy bleed rates: a completed audit loop. J Laryngol Otol 2008; 122(7): 719-21.

[87] Takwoingi YM, Shykhon M, Wake M. Effect of post-operative analgesia duration on post-tonsillectomy readmission rate: comparison of five-day and 14-day regime. J Laryngol Otol 2007; 121(10): 968-72.

[88] Tisch M, Bruder M, Maier H. Risk of postoperative hemorrhage in tonsillectomy. A comparison between general anesthesia and local anesthesia. HNO 2002; 50(3): 230-2.

[89] Windfuhr JP, Chen YS, Remmert S. Hemorrhage following tonsillectomy and adenoidectomy in 15,218 patients. Otolaryngol Head Neck Surg 2005; 132(2): 281-6.

[90] Clark MP, Waddell A. The surgical arrest of post-tonsillectomy haemorrhage: hospital episode statistics. Ann R Coll Surg Engl 2004; 86(6): 411-2.

[91] Windfuhr JP, Chen YS. Incidence of post-tonsillectomy hemorrhage in children and adults: a study of 4,848 patients. Ear Nose Throat J 2002; 81(9): 626-8, 30, 32 passim.

[92] Gamiz MJ, Lopez-Escamez JA. Preoperative markers for risk of post-tonsillectomy bleeding in adults. Acta Otorrinolaringol Esp 2000; 51(5): 407-11.

[93] Myssiorek D, Alvi A. Post-tonsillectomy hemorrhage: an assessment of risk factors. Int J Pediatr Otorhinolaryngol 1996; 37(1): $35-43$.

[94] Windfuhr JP, Schloendorff G, Baburi D, Kremer B. Serious posttonsillectomy hemorrhage with and without lethal outcome in children and adolescents. Int J Pediatr Otorhinolaryngol 2008; 72(7): 1029-40.

[95] Segal N, Puterman M, Rotem E, et al. A prospective randomized double-blind trial of fibrin glue for reducing pain and bleeding after tonsillectomy. Int J Pediatr Otorhinolaryngol 2008; 72(4): 469-73.

[96] Kumar VV, Kumar NV, Isaacson G. Superstition and posttonsillectomy hemorrhage. Laryngoscope 2004; 114(11): 2031-3.

[97] Haddow K, Montague ML, Hussain SS. Post-tonsillectomy haemorrhage: a prospective, randomized, controlled clinical trial of cold dissection versus bipolar diathermy dissection. J Laryngol Otol 2006; 120(6): 450-4.

[98] Pinder D, Hilton M. Dissection versus diathermy for tonsillectomy. Cochrane Database Syst Rev. 2001(4): CD002211.

[99] Collison PJ, Mettler B. Factors associated with post-tonsillectomy hemorrhage. Ear Nose Throat J 2000; 79(8): 640-2, 4, 6 passim.

[100] Shah UK, Galinkin J, Chiavacci R, Briggs M. Tonsillectomy by means of plasma-mediated ablation: prospective, randomized, blinded comparison with monopolar electrosurgery. Arch Otolaryngol Head Neck Surg 2002; 128(6): 672-6.

[101] Neumann C, Street I, Lowe D, Sudhoff H. Harmonic scalpel tonsillectomy: a systematic review of evidence for postoperative hemorrhage. Otolaryngol Head Neck Surg 2007; 137(3): 378-84.

[102] Tomkinson A, De Martin S, Gilchrist CR, Temple M. Instrumentation and patient characteristics that influence postoperative haemorrhage rates following tonsil and adenoid surgery. Clin Otolaryngol 2005; 30(4): 338-46.

[103] Bhattacharyya N, Kepnes LJ. Economic benefit of tonsillectomy in adults with chronic tonsillitis. Ann Otol Rhinol Laryngol 2002; 111(11): 983-8. 